\title{
DESENVOLVIMENTO DO PROCESSO DE LIMPEZA DE MEIO FILTRANTE CERÂMICO DE FILTROS INDUSTRIAIS *
}

\section{Resumo}

\author{
Phillipe Silva Alvarenga ${ }^{1}$ \\ Adail Mendes de Araújo Júnior ${ }^{1}$ \\ Ediron Antônio Lage ${ }^{1}$ \\ Aloísio Fonseca ${ }^{1}$ \\ Fabíola Teófilo Gomes ${ }^{1}$ \\ Paula Trindade Silva ${ }^{1}$ \\ Adarlan Moreira Silva ${ }^{1}$ \\ Marcelo Nazaro Silva ${ }^{2}$ \\ Henrique Dias Gatti Turrer ${ }^{3}$
} O complexo Minas-Rio da Anglo American iniciou suas operações em agosto de 2014. A usina de filtragem produziu, em 2016, cerca de 15 milhões de toneladas secas de concentrado. O minério, explorado no município de Conceição do Mato Dentro (MG), passa pelas etapas de cominuição, classificação, concentração e separação sólido-líquido antes de ser bombeado por $529 \mathrm{~km}$ até o município de São João da Barra (RJ), onde é filtrado, estocado e embarcado para exportação. Quatorze filtros cerâmicos, com $144 \mathrm{~m}^{2}$ de área de filtragem cada um, são responsáveis pelo último processo de produção do pellet feed. O início de operação foi marcado por um desempenho muito aquém do planejado. Diversos tipos de avaliações, como análises em microscópio ótico e contagem de bactéria, foram conduzidas e mostraram que o entupimento precoce dos poros do meio filtrante era o responsável pelo problema. Foram identificados 4 principais responsáveis pelo entupimento: material orgânico, sulfato de bário, partículas de concentrado de minério de ferro e óleo. Amostras de placas cerâmicas foram testadas em laboratório com diferentes reagentes para a limpeza dos poros entupidos. Análises químicas na solução resultante dessa lixiviação e/ou análise em microscópio dos corpos de prova indicavam a eficiência do reagente testado. Os mais promissores foram testados industrialmente. Por fim, o estabelecimento de uma nova rotina de limpeza das placas gerou uma melhora significava do desempenho da filtragem.

Palavras-chave: filtragem; placa cerâmica, pellet feed.

\section{DEVELOPING A CLEANNING PROCESS FOR THE CERAMEC FILTER MEDIA OF INDUSTRIAL FILTTERS}

\section{Abstract}

The Minas-Rio complex of Anglo American began operations in August 2014. The filtration plant produced, in 2016, about 15 million dry tons of concentrate. Ore, explored in the municipality of Conceição do Mato Dentro (MG), passes through the stages of comminution, classification, concentration and solid-liquid separation before being pumped by $529 \mathrm{~km}$ to the municipality of São João da Barra (RJ), where it is filtered, stored and shipped for export. Fourteen ceramic filters with $144 \mathrm{~m}$ 2 of filter area each are responsible for the last pellet feed production process. The beginning of operation was marked by performance much worse than the planned one. Various types of evaluations, as analyses in optical microscope and count of bacteria, were conducted and showed that early pores clogging of the filter medium was responsible for the problem. Four main causes have been identified for early clogging: organic material, barium sulfate, particles of iron ore concentrate and oil. Samples of ceramic plates were tested in the laboratory with different reagents for 
cleaning pores. Chemical analyses on resulting leached solution and/or microscope analysis of the bodies indicated reagent efficiency. The most promising were industrially tested. Finally, the establishment of a new routine of plates cleaning has resulted in an significant performance improvement.

Keywords: filtering; ceramec plate; pellet feed.

1 Gerência de filtragem, Anglo American - Fazenda Saco Dantas, $s / n^{\circ}$, Porto do Açú São João da Barra, Rio de Janeiro, Brazil.

2 Gerência de desenvolvimento de processos, Anglo American - Fazenda Saco Dantas, $s / n^{\circ}$, Porto do Açú São João da Barra, Rio de Janeiro, Brazil.

3 Gerência de desenvolvimento de processos, Anglo American - Rodovia MG 10, Km 180, Córrego Pereira, Conceição do Mato Dentro, MG, Brazil.. 


\section{INTRODUÇÃO}

O minério de ferro processado no complexo industrial do Minas-Rio, Anglo American, totalizou quase 15,5 milhões de toneladas de concentrado em 2016. O minério é extraído da jazida da Serra do Sapo em Conceição do Mato Dentro, MG. O processamento contempla as etapas de cominuição, por britadores de mandíbulas e grelhas, britadores cônicos e peneiras, prensas de rolos, moinhos de bolas e hidrociclones, seguido por deslamagem, flotação, remoagem em moinhos verticais (para adequação da granulometria de transporte), espessamento, bombeamento por $529 \mathrm{~km}$ de mineroduto e separação sólido-liquido para embarque, conforme figura 1 .

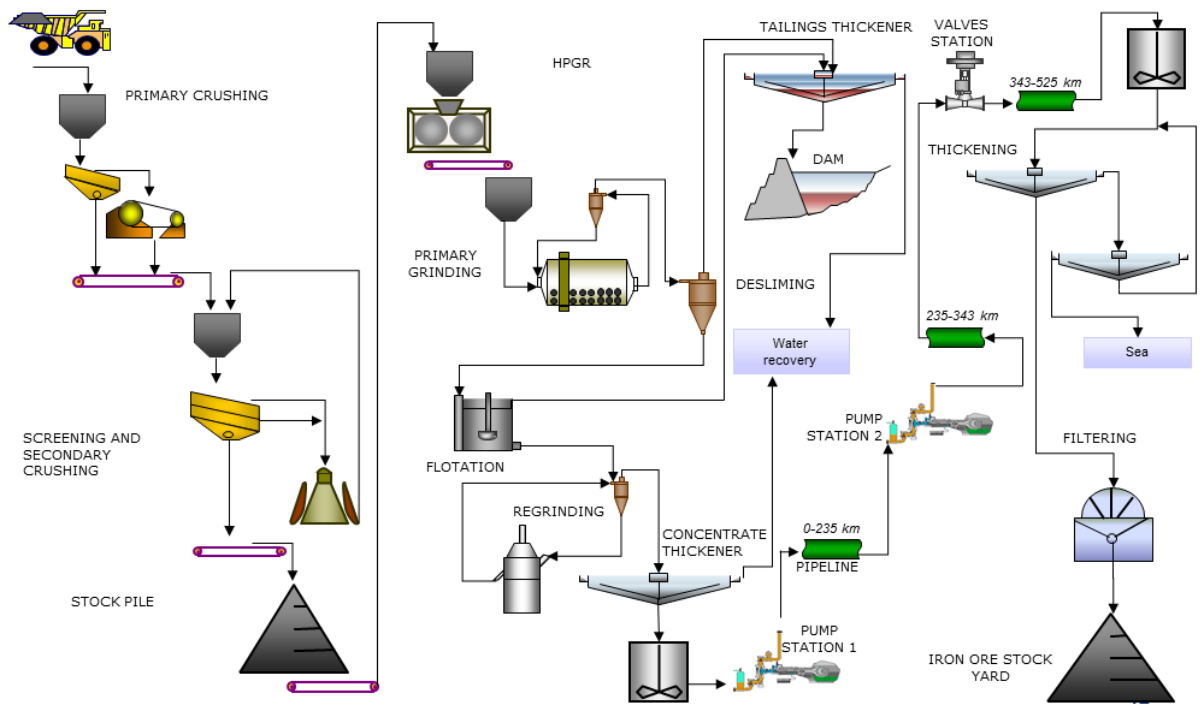

Figura 1. Fluxograma do processamento mineral no Minas-Rio.

O sistema Minas-Rio conta com a tecnologia desaguamento do pellet feed através da utilização de filtros cerâmicos fornecidos pela Outotec, modelo Ceramec CC-144, figura 2. Cada filtro possui 12 discos com 15 setores por filtro. Atualmente, a planta de filtragem possui 14 filtros em operação, totalizando 2520 placas e fazendo dessa unidade de filtragem responsável pela operação de mais de 50\% do quantitativo total mundial de filtros CC-144. Cada filtro possui um medidor de vazão de filtrado, o que permite determinar o desempenho individual dos mesmos de forma instantânea e quantitativa.

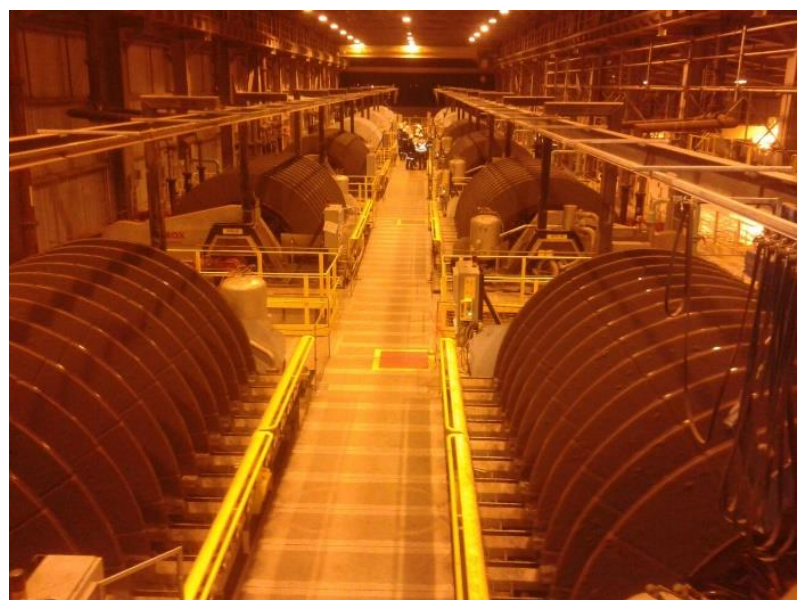

Figura 2. Filtros do Minas-Rio. 
O fornecedor dos equipamentos sugere um procedimento padrão de limpeza da placa, ou desobstrução dos capilares com cerca de $2 \mu \mathrm{m}$ de diâmetro, composto basicamente por lavagens periódicas com mistura de ácidos e utilização de ultrassom.

A limpeza com ultrassom consiste, basicamente, na aplicação do mesmo para retirada das partículas de concentrado que ficaram retidas nos poros do meio filtrante (Pirkonen et al.; 2010). Lamminen et al. (2004) apontaram o mecanismo de cavitação como principal responsável pelo descolamento das partículas da superfície do meio filtrante enquanto a turbulência associada ao ultrassom causa o transporte de partículas para fora do meio.

A precipitação de cálcio possui efeito significativo no entupimento dos poros de placas cerâmicas usadas na filtragem de minério de ferro (Salmimies et al.; 2011). Por isso esses filtros necessitam de limpeza com ácidos clorídrico, nítrico e sulfúrico, além de hidróxido de potássio para remoção do oxalato de cálcio, que é cristalizado nos poros cerâmicos devido à água e reagentes químicos utilizados no processo produtivo do concentrado (Salmimies et al.; 2013).

Nos dois processos industriais estudados por Salmimies et al. (2012b), produção de pellet feed a partir de minério hematítico ou magnetítico, somente no segundo o entupimento por precipitação química era significativo. Enquanto no primeiro somente sulfato de cálcio foi encontrado, no segundo foram encontrados, além desse composto, uma série de outros, como oxalato de cálcio e calcita. Foram ainda identificados três mecanismos de crescimento do precipitado: nucleação inicial, crescimento sobreposto e solidificação completa. Também apontaram a utilização de ácido oxálico de baixa qualidade como contribuinte para a precipitação desses compostos, além dos fatos mencionados no parágrafo anterior.

A limpeza com ácido oxálico de placas usadas na filtragem de concentrado de minério de ferro é necessária para solubilização das partículas de ferro retidas nos poros. Estudos conduzidos por Salmimies et al. (2012a) mostraram que uma maior permeabilidade foi obtida em placas limpas com soluções mais concentradas e em maiores temperaturas.

Contudo, cada processo produtivo tem suas particularidades. Muitas delas, acabam sendo desconhecidas durante a fase de projeto. O objetivo desse trabalho é apresentar todo o desenvolvimento realizado ao longo de mais de dois anos na Anglo American para desenvolvimento de um procedimento adequado para a limpeza das placas usados no processo produtivo do complexo do Minas-Rio.

\section{MATERIAIS E MÉTODOS}

Foram utilizadas diferentes técnicas para caracterização do material retido nas placas, como microscopia eletrônica de varredoura acoplada com espectrometria dispersiva de raio-x, espectrometria de emissão atômica por plasma acoplado indutivamente, contagem de bactérias e determinação de óleo e graxa pelo método de extração de Soxhlet em laboratórios fora do complexo industrial do Minas-Rio. A turbidez foi determinada por absorbância de raio luminoso em turbidímetro portátil. 
Os testes com reagentes de limpeza foram realizados de formas variadas, como:

i. Utilização do próprio sistema de limpeza já existente nos filtros, que faz uma retrolavagem das placas com a solução testada, conforme explicado por Savolainen et al. (2011);

ii. Adição do reagente na bacia do filtro industrial;

iii. Imersão de placa inteira em bacia e sucção da solução até garantir que o filtrado esteja com turbidez adequada, seguido de limpeza ultrassónica. Imersão de pedaços das placas em béqueres com solução dos reagentes;

iv. Imersão de pequenos corpos de prova em béqueres com soluções dos reagentes.

Dados de vazão do filtrado por filtro e produção da filtragem foram medidos por instrumentos instalados na usina (medidores de vazão e balanças) e gravados no sistema de informações de controle do processo (PIMS).

\section{RESULTADOS E DISCUSSÃO}

No início da operação da filtragem em 25 de agosto de 2014, o ciclo de regeneração de placa cerâmica consistia de limpeza combinado (química + ultrassom) com o uso de ácido nítrico, na concentração de $1 \% \mathrm{w} / \mathrm{w}$, e oxálico, $3 \% \mathrm{v} / \mathrm{v}$, com o objetivo de evitar o entupimento devido a depósitos de carbonatos e resíduos ferrosos respectivamente. No entanto, foi observado uma queda gradual da permeabilidade de placas, mesmo após a limpeza combinada, figura 3.

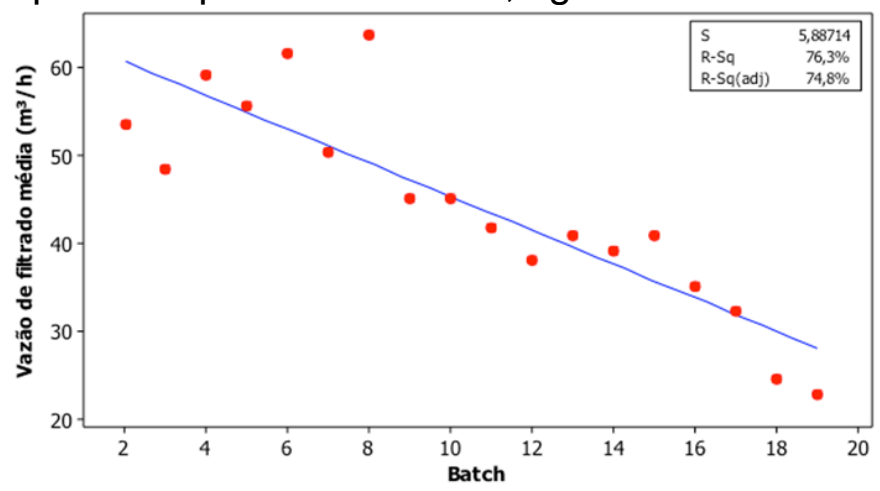

Figura 3. Queda da permeabilidade da placa do filtro 8.

Diversas soluções foram testadas para verificar a eficiência de limpeza das placas. As mesmas eram adicionadas a bacia do filtro no momento da lavagem. Dessas, somente o hipoclorito de sódio, $\mathrm{NaClO}$, apresentou efeito significativo, figura 4. Além disso, foi feito uma contagem de bactérias na superfície das placas antes e depois da aplicação do $\mathrm{NaClO}$, tabela 1, confirmando que a causa de entupimento era orgânica. 


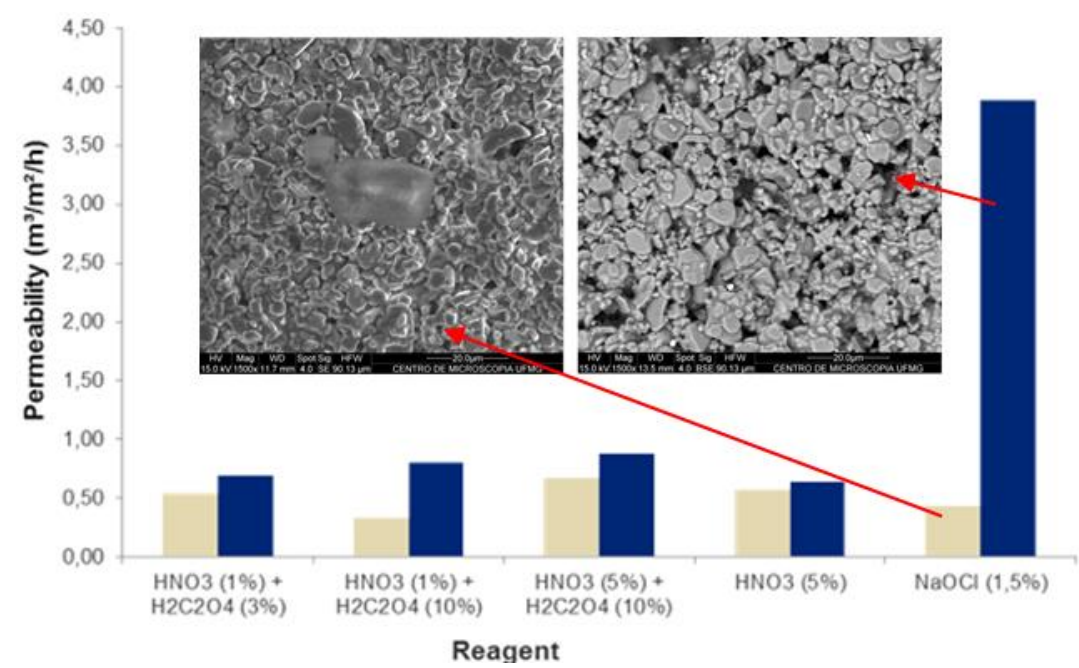

Figura 4. Aumento da permeabilidade das placas após limpeza com hipoclorito.

Tabela 1. Resultado da contagem de bactérias na placa antes e após lavagem com $\mathrm{NaClO}$

\begin{tabular}{|l|l|c|c|}
\hline Parâmetros & Antes da lavagem & Depois da lavagem \\
\hline Descrição & Unidade & Resultados & Resultados \\
\hline Bactéria aeróbica & $20 \mathrm{~cm}^{2}$ & 16.000 .000 & 11.400 \\
\hline Bactéria anaeróbica & $20 \mathrm{~cm}^{2}$ & 2.680 .000 & 2.700 \\
\hline bactérias redutoras de sulfato & $20 \mathrm{~cm}^{2}$ & 13 & 17 \\
\hline Coliformes totais & $20 \mathrm{~cm}^{2}$ & 9.200 .000 & 15.000 \\
\hline Escherichia coli & $20 \mathrm{~cm}^{2}$ & 17.000 & 1.400 \\
\hline Fungi & $20 \mathrm{~cm}^{2}$ & 3.970 & 1.270 \\
\hline
\end{tabular}

Contudo, alguns meses depois, essa lavagem parou de ser efetiva. Novas análises de microscopia eletrônica indicaram a formação de compostos de bário próximo a superfície das placas, conforme mostrado na figura 5. Mais uma vez foram testados diferentes reagentes nas placas que perderam permeabilidade. $O$ ácido etilenodiamino tetra-acético, EDTA, foi o que resultou em efeito mais significativo. $\mathrm{O}$ tempo de limpeza e a concentração foram avaliados qualitativamente com pedaços de placas industriais, figura 6 .
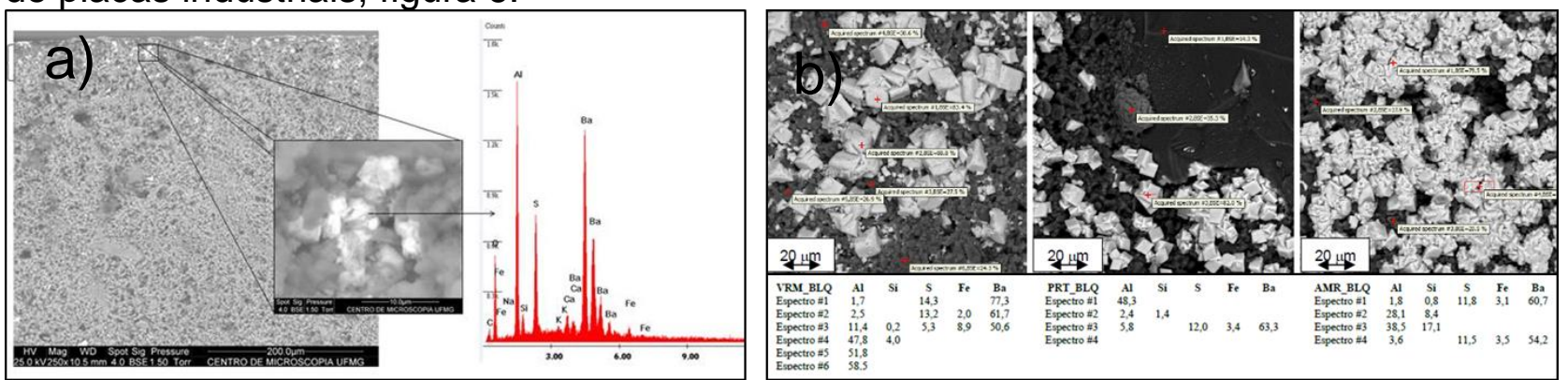

Figura 5. Composto de bário em placas cerâmicas, corte lateral (a) e superfície filtrante (b). 

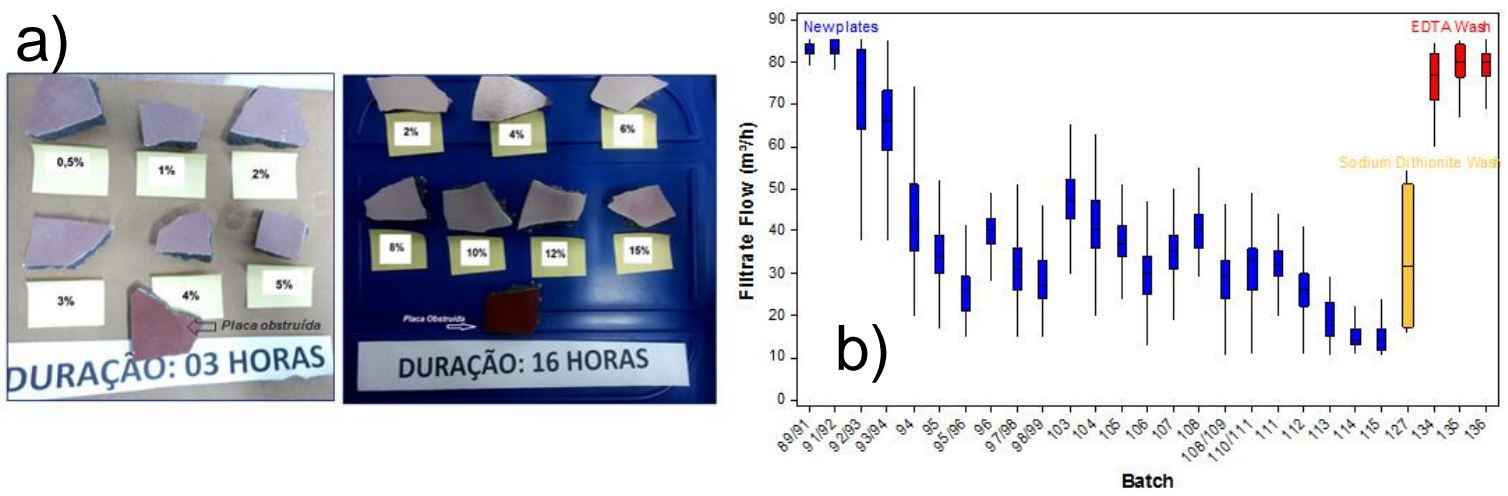

Figura 6. Teste para avaliação do tempo de limpeza e concentração do EDTA (a) e permeabilidade do filtro 4 após limpeza com o mesmo (b).

Contudo, os filtros voltaram a apresentar uma tendência de diminuição da produtividade no segundo semestre de 2015 , quando cal passou a ser usada como controlador da reologia no mineroduto e, para evitar a formação de oxalatos de cálcio, a adição de ácido oxálico foi suspensa. Essas placas foram então removidas e regeneradas num sistema a parte. $O$ reagente que apresentou 0 melhor desempenho foi o Kleen MCT405 da GE, comumente utilizado em limpezas em membranas em plataformas de petróleo para remoções específicas de certos slimes bacteriológicos e para remover materiais coloidais inorgânicos e, ao mesmo tempo, já dispersá-los na solução. Uma série de testes indicou os parâmetros para maximizar a limpeza da placa, figura 7.
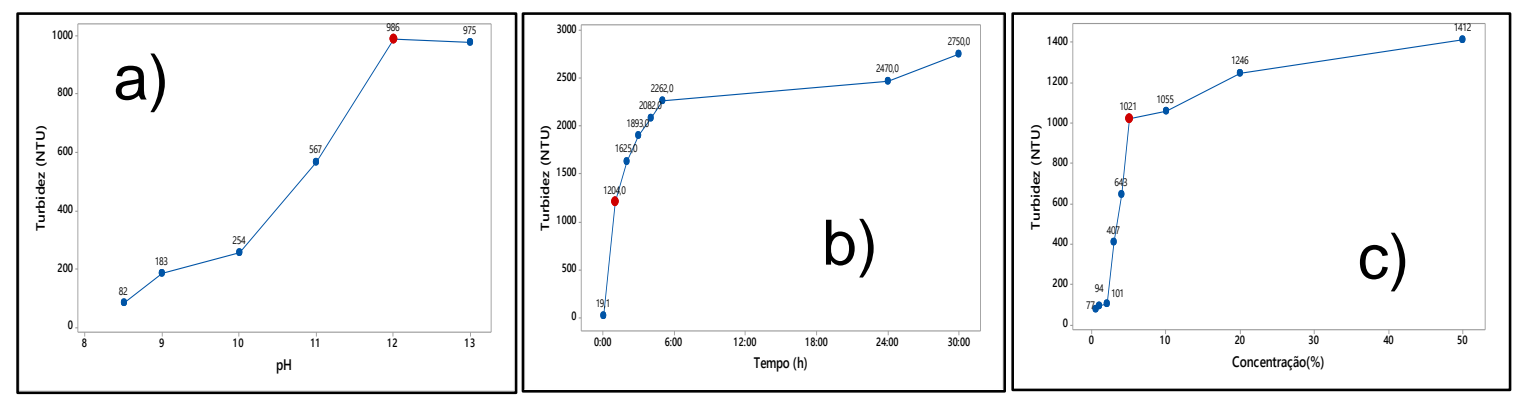

Figura 7. Influência do pH (a), tempo de exposição (b) e concentração da solução (c) na remoção das partículas que entupiam a placa.

Análises em microscópio eletrônico associada à química indicaram a presença de partículas de ferro na superfície das placas, figura 8a. A análise química do filtrado, figura $8 \mathrm{~b}$, confirmou essas suspeitas.
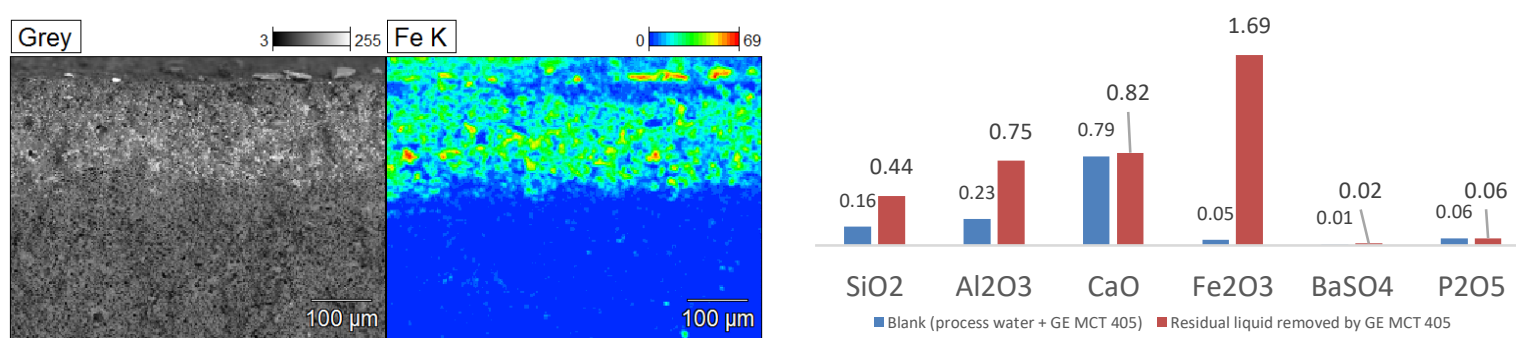

Figura 8. Imagem em MEV-EDS do corte lateral de placas entupias (a) e análise química, em ppm, do filtrado obtido durante o processo de limpeza das mesmas (b). 
As placas submetidas a essa limpeza foram colocadas em um filtro. Diante do bom resultado exibido, outros 3 filtros foram substituídos com placas limpas dessa forma. Durante esse período de troca de placas foi observado uma elevação gradativa da produtividade da filtragem, com um aumento de cerca de $70 \%$, superando até mesmo o critério de projeto de $1,7 \mathrm{t} / \mathrm{m}^{2} / \mathrm{h}$, figura 9 .

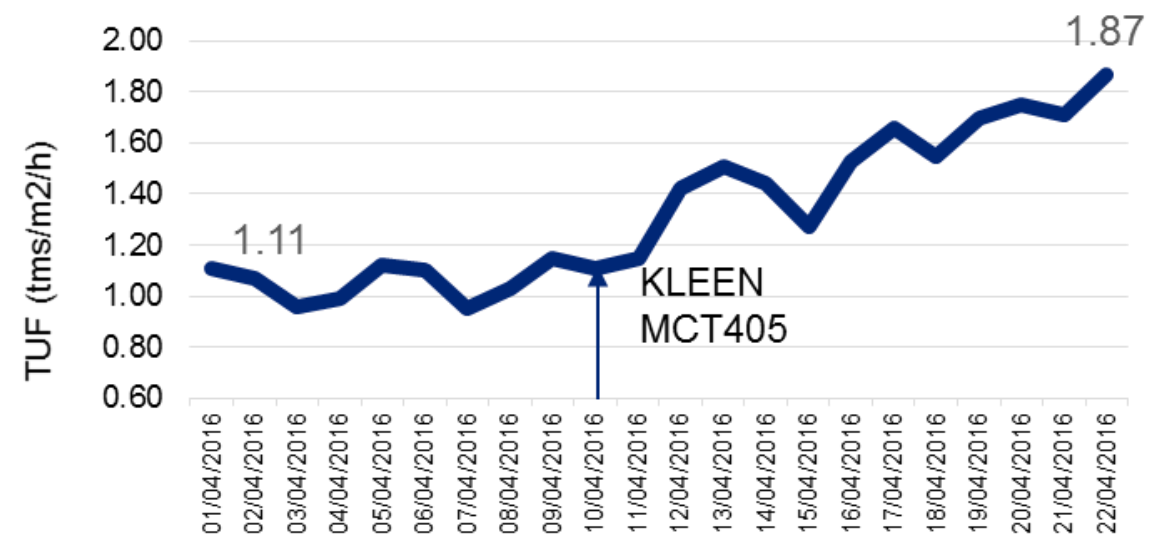

Figura 9. Produtividade da filtragem após o início de lavagem de placas com Kleen MCT405.

No início de 2016, mais uma vez, a produtividade dos filtros começou a apresentar tendência de queda e o procedimento de lavagem desenvolvido até então não surtia o efeito esperado. Dessa vez, percebeu-se visualmente a presença de óleo na polpa. Medidas de óleo e graxas confirmaram essa suspeita, indicando a presença de 20 ppm no filtrado. Mais uma vez placas foram retiradas e reagentes testados, em pedaços quebrados de placa e em placas inteiras imersas na solução do reagente, para verificar a eficácia na regeneração da mesma. Esses testes indicaram que a a utilização de solução do Spectrus BD1501E da GE, preparado na concentração de $5 \%$ e pH 12. Inicialmente isso foi confirmado pela turbidez do filtrado produzido durante a limpeza das placas, figura 10. Em seguida, a eficácia do reagente foi testada em um filtro industrial que estava apresentando baixo desempenho, figura 11.
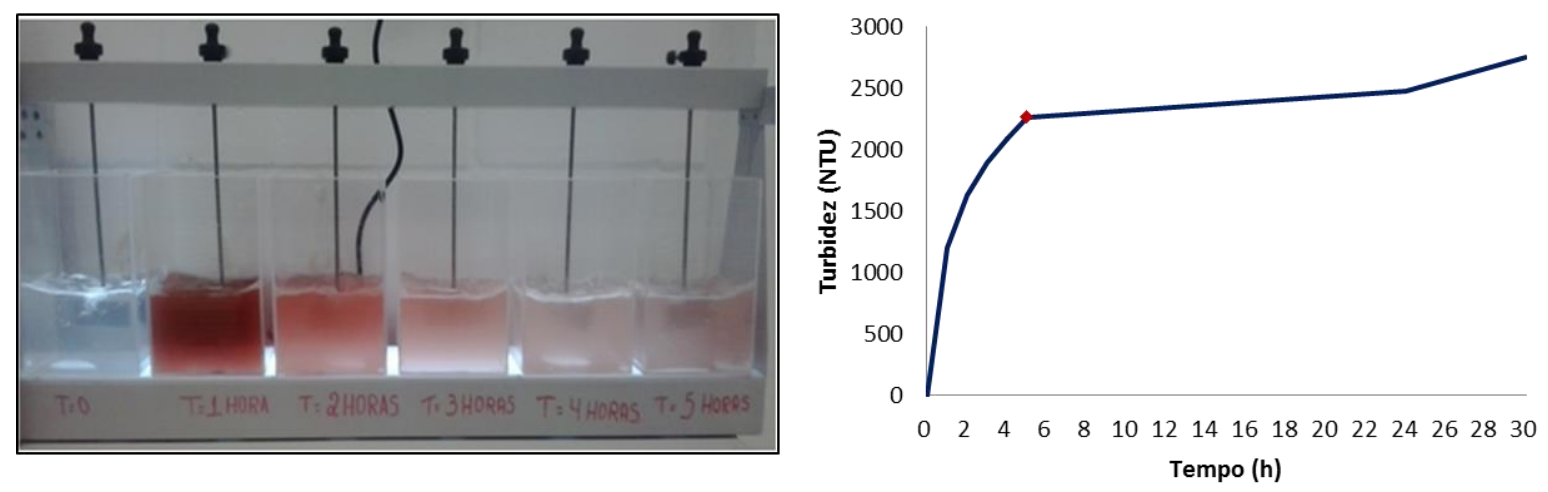

Figura 10. Produtividade da filtragem após o início de lavagem de placas com Kleen MCT405. 
Filter 01 - Filtrate Flow $\left(\mathrm{m}^{3} / \mathrm{h}\right)$

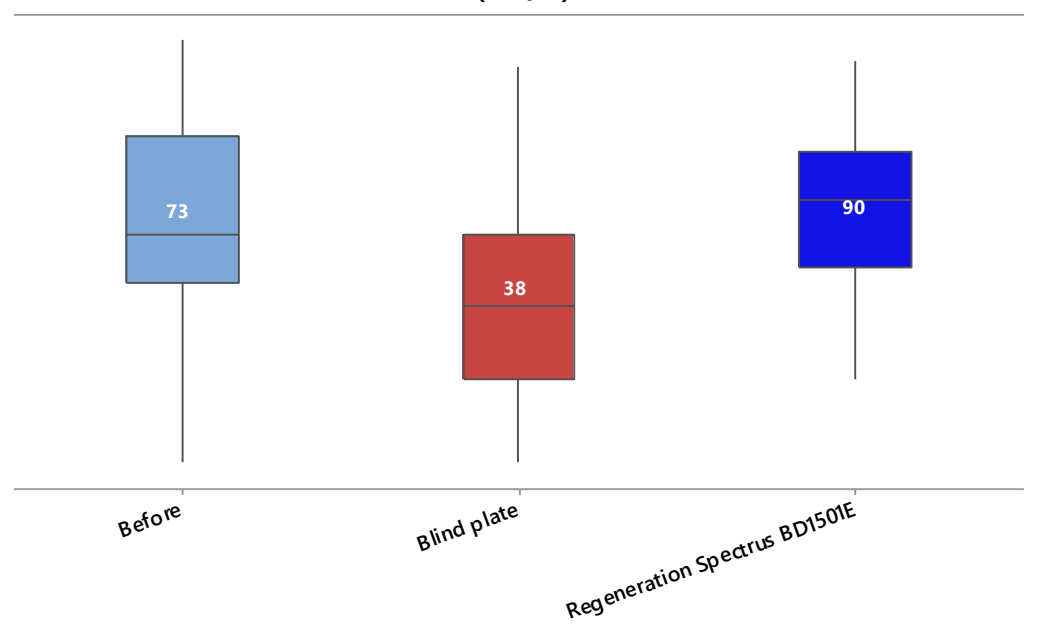

Figura 11. Taxa de filtrado $\left(\mathrm{m}^{3} / \mathrm{h}\right)$ do filtro 1 antes e durante de entupimento por óleo, além do período após limpeza das placas com Spectrus BD 1501E.

As figuras 12 e 13 resumem o efeito desses desenvolvimentos, respectivamente, na produtividade e no consumo de placas da filtragem ao longo de sua operação.

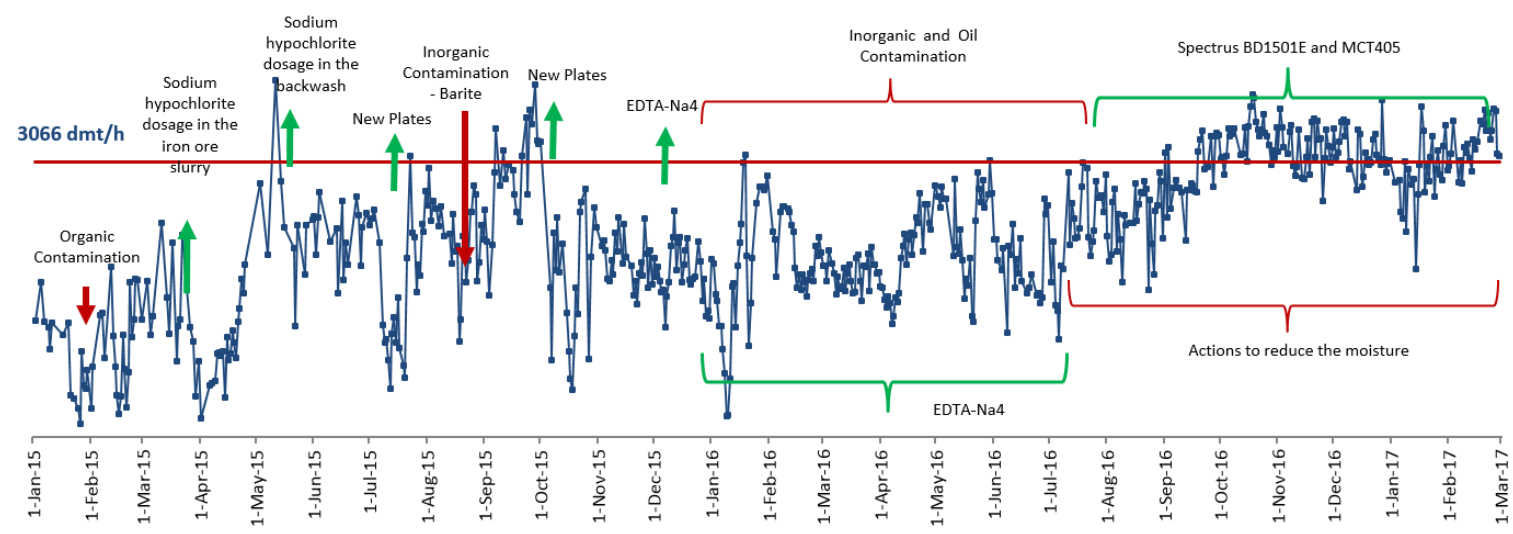

Figura 12. Evolução da produtividade da filtragem do Minas-Rio.

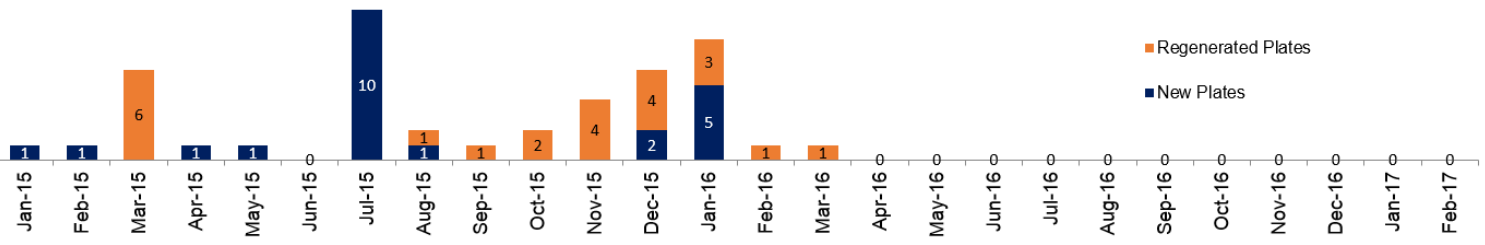

Figura 13. Quantidade de filtros que tiveram placas trocadas por baixa produtividade por mês.

Esses resultados estão sendo sustentados pelo procedimento de limpeza descrito a seguir e realizado pelo próprio sistema de retrovalagem do filtro:

- A cada 8 horas de limpeza, ocorre a lavagem alternada com o ácido nítrico e hipoclorito. O primeiro é usado por 55 minutos e o segundo por 45 minutos. Ambos fazem uso do ultrassom, por 15 minutos seguidos, que se alternam com 15 minutos de limpeza sem o mesmo. 
- Nos finais de semana, os filtros que apresentam baixa permeabilidade (menor que $70 \mathrm{~m}^{3} / \mathrm{h}$ ) passam pela seguinte sequência de limpeza: EDTA por 24 horas, Kleen MCT405 por 6 horas e Spectrus BD 1501E por 2 horas. Nesses casos, a limpeza só com ultrassom ocorre por 2, 1 e 2 horas, respectivamente, após a limpeza com EDTA, Kleen MCT405 e Spectrus BD 1501E.

\section{CONCLUSÃO}

Conclui-se que a tecnologia de filtragem cerâmica é tecnicamente viável para a filtragem do pellet feed produzido pelo complexo do Minas-Rio. A manutenção da produtividade de placas e extensão da vida útil é garantida com a utilização de procedimentos desenvolvidos especificamente para o processo produtivo em questão.

\section{REFERÊNCIAS}

1 Lamminen, M.O.; Walker, H.W.; Weavers, L.K. (2004) Mechanisms and factors influencing the ultrasonic cleaning of particle-fouled ceramic membranes. Journal of Membrane Science, v.237, p.213-223.

2 Pirkonen, P.; Grönroos, A.; Heikkinen, J.; Ekberg, B. (2010) Ultrasound assisted cleaning of ceramic capillary filter. Ultrasonics Sonochemistry, n.17, p.1060-1065.

3 Salmimies, R,; Kallas, J.; Ekberg, B.; Görres, G.; Andreassen, J.P.; Beck, R. (2013) The scaling and regeneration of the ceramic filter medium used in the dewatering of a magnetite concentrate. International Journal of Mineral Processing, n.119, p.21-26.

4 Salmimies, R.; Hakkinen, A.; Kallas, J.; Ekberg, B.; Andreassen, J.P.; Beck, R. (2011) Characterization of long term scaling effects of ceramic filter media used in the dewatering of iron ore. In: Iron Ore Conference, p.521-527.

5 Salmimies, R.; Kallas, J.; Ekberg, B.; Hakkinen, A. (2012a) Oxalic acid regeneration of ceramic filter medium used in the dewatering of iron ore. ISRN Chemical Engineering, 6p.

6 Salmimies, R.; Kallas, J.; Ekberg, B.; Hakkinen, A. (2012b) Scale growth in the dewatering of iron ore. International Journal of Mining Engineering and Mineral Processing, v.1, n.2, p.69-72.

7 Savolainen, M.; Huhtanen, M.; Häkkinen, A.; Ekberg, B.; Hindström, R.; Kallas, J. (2011) Development of testing procedure for ceramic disc filters. Minerals Engineering, n.24, p.876-885.. 